\title{
FORMAÇÃO DO PSICÓLOGO CLÍNICO NA PERSPECTIVA FENOMENOLÓGICO-EXISTENCIAL: DILEMAS E DESAFIOS EM TEMPOS DE TÉCNICAS ${ }^{1}$
}

\author{
Formation of Clinical Psychologist in Phenomenological-Existential Perspective: \\ Dilemma and Challenges in Technical Times \\ Formación del Psicólogo Clínico en la Perspectiva Fenomenologico-Existencial: \\ Dilemas y Desafíos en Tiempos de Técnicas
}

Elza Dutra

\begin{abstract}
Resumo: Este trabalho desenvolve reflexões sobre formação do psicólogo clínico na perspectiva fenomenológico-existencial, numa época em que a técnica prevalece, inclusive no campo da psicologia clínica. Tomando como referência a fenomenologia hermenêutica heideggeriana, reflete-se sobre os desafios que perpassam as práticas clínicas ao longo da formação de aprendizes de psicoterapeutas, ao lidarem com demandas de respostas imediatas e eficientes que frequentemente são dirigidas à clínica. No sentido oposto ao cenário cientificista que sustenta a psicologia, a perspectiva adotada neste trabalho aponta para uma atitude fenomenológica, a qual vai de encontro à atitude natural, valorizando, assim, a idéia de um Dasein que existe num horizonte de abertura de sentidos e sobre o qual não caberia qualquer determinação. Algumas ideias heideggerianas como Dasein, ser-com, técnica e pensamento meditante nortearão as reflexões. Finaliza-se sugerindo que o âmbito da formação constitua um espaço no qual o pensamento que medita possa ser exercitado como uma das possibilidades para se desenvolver uma atitude fenomenológica. Palavras-chave: Heidegger e psicologia; Formação clínica; Pensamento meditante e clínica; Clínica fenomenológica e Técnica.
\end{abstract}

Abstract: This paper develops reflections on training of the clinical psychologist in existential-phenomenological perspective, at a time when the technique prevails, even in the field of clinical psychology. Referring to Heidegger's hermeneutic phenomenology, reflects on the challenges that underlie clinical practices throughout the apprenticeship training of psychotherapists, in dealing with demands immediate and effective responses that are often directed to the clinic. In the opposite scenario holds that scientistic psychology, the perspective adopted in this paper points to a phenomenological attitude, which goes against the natural attitude, thus valuing the idea of a Dasein that exists opening a horizon of meaning and on which would not fit any determination. Some heideggerians ideas as Dasein, being-with, technique and thought meditator guide the reflections. Ends up suggesting that the scope of training constitutes a space in which the thought that meditation may be exercised as one of the possibilities to develop a phenomenological attitude.

Keywords: Heidegger and psychology; Clinical training; Thought meditator in the clinic; Clinical phenomenology and technique.

Resumen: En este trabajo se desarrolla reflexiones sobre la formación del psicólogo clínico en la perspectiva-fenomenológicaexistencial, en momentos en que la técnica se impone, incluso en el campo de la psicología clínica. En referencia a la fenomenología hermenéutica de Heidegger, reflexiona sobre los desafíos que subyacen a las prácticas clínicas en toda la formación de aprendices de psicoterapeutas, para hacer frente a las demandas inmediatas y respuestas efectivas que a menudo se dirigen a la clínica. En la situación opuesta a lo cenario que sostiene la psicología cientificista, la perspectiva adoptada en este trabajo apunta a una actitud fenomenológica, que va en contra de la actitud natural, valorando así la idea de un Dasein que existe en el horizonte de apertura de sentido y que no se ajusta a cualquier determinación. Algunas ideas heideggerianas como Dasein, el ser-con, la técnica y el pensamiento meditante guían las reflexiones. Termina sugiriendo que el ámbito de la formación constituye un espacio en el que la idea de uno pensamiento meditante puede ser ejercido como una de las posibilidades para el desarrollo de una actitud fenomenológica.

Palabras-clave: Heidegger y la psicologia; La formación clínica; Pensamiento meditante en la clínica; Clínica fenomenológica y técnica.

\section{Introdução}

Neste trabalho pretendo prosseguir com as reflexões empreendidas ao longo dos últimos anos: a formação do psicólogo clínico na perspectiva fenomenológico-existen-

\footnotetext{
Trabalho apresentado no I Congresso Brasileiro de Psicologia Fenomenológica, realizado em Curitiba- PR, na UFPR, agosto de 2013.
}

cial. As discussões sobre essa temática vêm sendo atualizadas constantemente, no âmbito da prática clínica, do ensino e da supervisão de estágio. Embora a psicologia clínica ocupe um espaço bastante consolidado no campo das práticas psicológicas, considero que a formação do psicólogo clínico ainda é um tema não suficientemente tematizado nos contextos acadêmico e profissional. Neste 
texto pretendo dirigir a reflexão na direção de alguns aspectos que perpassam a formação do psicólogo clínico na perspectiva fenomenológico-existencial, entendendo que essa formação ocorre, inevitavelmente, a partir da experiência do psicólogo, sendo esta, a experiência, aquela que embasará o que se chama, na perspectiva fenomenológico-existencial, de atitude fenomenológica.

Tenho constatado que tanto supervisores quanto aprendizes de psicoterapeutas, no exercício de práticas clínicas, e, muito frequentemente, ao depararem com demandas de respostas imediatas e eficientes que comumente lhes são dirigidas, percebem-se caminhando na contramão dessa tendência, tão comum nos dias atuais, ao adotarem uma perspectiva como a fenomenológico-existencial. No sentido oposto ao cenário cientificista que ainda prevalece no campo da psicologia, a perspectiva abordada aqui aponta para uma atitude fenomenológica, a qual contraria a atitude natural, esta que subsidia, em grande parte, o aporte epistemológico cientificista sobre o qual a psicologia se pautou desde quando se afastou do campo da filosofia, passando a adotar o paradigma científico. Contrariamente à dimensão científica da psicologia, a perspectiva fenomenológica com base na fenomenologia hermenêutica heideggeriana, considera a idéia de um Dasein que existe num horizonte de abertura de sentidos e sobre o qual não caberia qualquer determinação, como apontam os pressupostos de uma ciência que adota como critérios de rigor a objetividade, generalização, controle e previsibilidade, por exemplo.

As reflexões feitas, as quais, na verdade, as considero mais como interrogações e estranhamentos que desejo partilhar com aqueles envolvidos com o tema, dizem respeito ao âmbito da formação de graduandos e psicólogos que desejam seguir a prática clínica numa perspectiva que, nos dias atuais, foge quase que totalmente, ao "espírito de época"2. A despeito do longo tempo e experiência nas atividades de ensino, de psicoterapeuta e como supervisora de estágio, ainda me vejo vivenciando uma sensação de estranheza diante dos acontecimentos do mundo, os quais, obviamente, repercutem em nossas práticas profissionais. Isso porque vivemos um tempo de grandes avanços tecnológicos, em todos os campos. Podemos dizer que a ciência evoluiu tão celeremente que embora ainda não se tenha acesso à cura do câncer, já é possível congelar o nosso corpo, esperando recuperá-lo no futuro, livre de algumas doenças. Ao mesmo tempo, a indústria farmacêutica oferece uma gama de fármacos que visam a curar e aliviar os males do corpo, e também os da alma. Enquanto isso, a tecnologia, já adotada pela psicologia, oferece tratamentos por meio de aparelhos de biofeedback, com a promessa de curar ansiedades, enxaquecas, estresses e ou-

\footnotetext{
Tradução do termo alemão Zeitgeist, significando o clima cultural e intelectual que marcam determinada época no mundo.
}

tros mal-estares que acometem as pessoas, numa cultura regida pela ética do consumo e do descartável. No mundo contemporâneo é possível transformar o corpo como se fora uma massa de modelar, esculpindo-o até ao formato ideal a que os desejos idealizados e alimentados pela cultura midiática conduzem. Escolhemos um corpo e um modo de ser como se estivéssemos numa grande loja de departamentos, onde as prateleiras, repletas de mercadorias, nos convidam e nos atraem, num jogo de sedução ao qual, muitas vezes, cedemos, sem muito pensar. Sim, pensar é uma palavra chave nesse espaço de reflexão e ao qual retornarei adiante.

Não tenho dúvidas de que vivemos uma época em que a técnica, no sentido moderno - tal como entendida por Heidegger (1953/2001), no seu ensaio A Questão da Técnica - como um modo de desencobrimento, porém no sentido de extração, exploração e cálculo, prevalece, inclusive no campo da psicologia clínica. Desse modo, por meio de uma cultura tecnicista, a ciência tem cumprido o seu papel, buscando respostas para os problemas e males humanos, ou seja, para o sofrimento. Aqui cabe trazer uma ideia do filósofo acerca do tipo de pensamento que permeia a cultura ocidental. Para ele, nessa cultura, o tipo de pensamento que reinaria seria o pensamento calculante, o qual se caracteriza pelo cálculo; e ainda que tal pensamento não se opere com máquinas e números, envolve o planejamento e calcula. Como diz ele, "Este cálculo caracteriza todo o pensamento planificador e investigador" (Heidegger, 1959, p. 13). Por isso ele torna-se adequado aos afazeres e práticas cotidianas, que pedem urgência, eficiência e rapidez na eliminação do sofrimento. Assim, tal modo de pensamento embasaria a técnica, tal como concebida no mundo atual.

A técnica, no sentido moderno e que tem como princípio a instrumentalidade, tem sido considerada a solução também para as doenças da alma e para os mal-estares que acometem o homem contemporâneo. No entanto é importante pensar que esse homem, constituído e constituinte de um mundo no qual prevalece a cultura do narcisismo e do consumo, vê-se perdido, desenraizado e em busca de um sentido para a sua existência. Ideia esta que nos remete a Figueiredo (1996), para quem o homem contemporâneo estaria vivendo uma experiência de "desterritorialização", tornando-nos "sobreviventes" numa sociedade sem rumo. Em razão do que, não bastam os psicofármacos cada vez mais potentes, os aparelhos de biofeedback extremamente sofisticados ou mesmo técnicas terapêuticas cada vez mais eficientes e breves, que consigam eliminar o sofrimento desse homem. Se assim fosse, não teríamos estatísticas, cada vez mais significativas, de doenças expressivas do nosso tempo, como a depressão, as fobias, as síndromes do pânico, o suicídio, além das manifestações de violência, as quais podem ser interpretadas como falta de sentido, busca de 
alteridade, resultado da fratura social, como bem coloca Safra (2004). Isso porque estamos lidando com a complexidade de um ser que atribui sentidos à sua existência e, portanto, singular. Assim, haverá, sempre, algo que ficará de fora do representado, o imponderável, aquilo que não se prevê e nem se deixa controlar; melhor dizendo, algo não dito e cujos sentidos se desvelam à medida que somos-no-mundo. Refiro-me a algo que escapa às verdades estabelecidas, aquelas originadas de uma perspectiva que coisifica o homem e desconsidera a sua capacidade de ser e existir num mundo de possibilidades e indeterminação.

\section{Dasein, ser-no-mundo e atitude fenomenológica na clínica}

Na cultura contemporânea, regida pelos avanços científicos e pelos aparatos técnicos, a psicologia busca consolidar os seus espaços no universo científico. Uma vez encontrando-se fundamentada, historicamente, no paradigma científico tradicional das ciências naturais, cria a exigência de uma clínica psicológica que atenda aos critérios de cientificidade adotados por ela. Porém, considerando a dispersão do campo, como bem nomeiam Figueiredo \& Santi (2000), nem sempre isso é possível e exeqüível. Para os autores, “(...) a ciência moderna está baseada na suposição de que o homem é o senhor que tem o poder e o direito de colocar a natureza a seu serviço" (p. 54).

Entretanto, ao se adotar uma perspectiva fenomenológica - nesse caso, a fenomenologia hermenêutica heideggeriana - tal propósito perde o sentido, uma vez que essa perspectiva aborda o Dasein na sua irredutível condição de indeterminação e poder-ser; com isso, afasta-se radicalmente dos critérios tradicionais de cientificidade. Fica evidente, portanto, que o desenvolvimento de uma postura ou atitude fenomenológica remete a pressupostos e fundamentos filosóficos e epistemológicos distintos daqueles apontados pela psicologia dita científica. Estes, têm como base as ideias que fundamentam a ontologia fundamental proposta por Martin Heidegger, entendendo que o Dasein se encontra, sempre e inevitavelmente, numa abertura de sentidos que se desvela em sua facticidade e à qual ele responde com o que lhe é mais próximo, isto é, a sua experiência; o que significa dizer, com a sua condição de ser-no-mundo.

Com isso, algumas interrogações daí se originam: como ocorre a formação de um psicólogo clínico nesta perspectiva, sabendo-se que a atitude fenomenológica representa um modo-de-ser e, portanto, inacessível a qualquer objetivação? Até que ponto é possível desenvolver uma atitude que se ampara na experiência, e que se dá, originariamente, na existência, sabendo-se que esta é fluida, provisória e impossível de ser objetivada? Além do que, esta atitude, como é sabido por aqueles que se iden- tificam com as perspectivas fenomenológicas e existenciais, não se alcança exclusivamente por meio das teorias psicológicas, das filosofias, mas, sobretudo, da reflexão meditante sobre a experiência de ser-no-mundo. Como, então, lidar com a atitude natural que perpassa, de uma maneira geral, a maioria dos currículos do curso de psicologia e que inevitavelmente, incide nas práticas psicológicas clínicas? Como sensibilizar o aprendiz de psicoterapeuta no sentido da desconstrução de um saber técnico sobre o qual a Psicologia, como ciência e profissão, se encontra, tradicional e historicamente assentada? Enfim, como desenvolver uma atitude fenomenológica sem que esta corra o risco de se transformar em mais uma técnica?

Oportuno lembrar, no que respeita à formação do psicólogo que, no contexto acadêmico, as grades curriculares dos cursos de psicologia, de maneira geral, solicitam dos seus professores disciplinas teóricas, trabalho em equipe com outras perspectivas teóricas, estágio supervisionado em ênfases que buscam integrar práticas oriundas de campos epistemológicos diversos, por exemplo. Ou seja, transitamos por um universo acadêmico primordialmente orientado por parâmetros técnicos (Dutra, 2009), o que demanda um discurso que seja compreensível não só para os nossos pares da fenomenologia, mas também para aqueles de orientações diversas. Ao mesmo tempo, é necessário preservar o espaço de saberes e fazeres num campo de dispersão epistemológica, como o da psicologia. Com isso, uma pergunta retorna: o que fundamentaria uma formação clínica na perspectiva fenomenológico-existencial?

\section{Sobre a formação}

Para início de conversa, é pertinente questionar o uso do termo "formação", no contexto da perspectiva em questão. O que significa "formar"? Caberia nos referirmos a "formação" quando tratamos da perspectiva em questão? Considerando que o vocábulo formar, segundo o dicionário Aurélio (2013), é definido como a "ação ou efeito de formar-se; Modo por que uma coisa se forma", podemos aceitar tal termo como adequado. Mas se tomarmos esta palavra no sentido de um estado final, acabado, formado, significando que alguém está pronto, resolvido, então não cabe a referência ao termo formação. Entretanto, por todas as ideias já apresentadas neste trabalho, presume-se que não se trata de formação neste sentido, quando nos referimos à perspectiva objeto das reflexões. Neste trabalho o termo formação é entendido como um processo, o qual comportaria, sem dúvidas, a concepção de uma experiência existencial, de um poder-ser, portanto, inacabada.

Com isso, cabe interrogar então: em que consistiria uma formação clínica nessa abordagem? Se pensássemos em critérios para uma boa formação, direcionada à formação do psicólogo clínico de uma maneira geral, esta já seria uma tarefa complicada. Isso porque nos depararíamos, certamente, com a conhecida e reconhecida diver- 
sidade da psicologia. Assim, como pensar uma formação que leve em conta critérios que contemplem e reflitam tal diversidade? Como é possível pensar em habilidades e competências do psicoterapeuta se reconhecemos a existência de perspectivas teóricas e metodológicas bastante divergentes e, muitas vezes, até, inconciliáveis, se considerarmos os campos epistemológicos que as sustentam? Se interrogássemos psicoterapeutas de orientação psicanalítica, humanista e cognitivo-comportamental, por exemplo, sobre as características de um bom psicoterapeuta, certamente teríamos respostas muito distintas. Reiterando a ideia de que a concepção de formação e de clínica varia muito, dependendo do horizonte teórico e metodológico de onde se originam. Neste momento é oportuno trazer as ideias de Figueiredo (1993) acerca da dispersão da psicologia. O autor, além de reconhecer a "multiplicidade oficial da psicologia", entende que mesmo no âmbito das teorias e das práticas psicológicas existiria um tipo de conhecimento, o tácito, integrando a experiência, a todo o momento. Sobre o conhecimento tácito, assim ele o define:

O conhecimento tácito do psicólogo é o seu saber de ofício, no qual as teorias estão impregnadas pela experiência pessoal e as estão impregnando numa mescla indissociável; este saber de ofício é radicalmente pessoal, em grande medida intransferível e dificilmente comunicável. O resultado é que a adesão explícita a uma 'escola' diz muito pouco da efetiva atuação profissional; na verdade, creio que quanto mais conta a experiência, quanto mais tempo no exercício da profissão, mais as variáveis pessoais vão pesando na definição das práticas e das crenças dos psicólogos. (Figueiredo, 1993, p. 91).

Ele segue discutindo o tema da multiplicidade de fazeres, saberes e encontro com as alteridades. E assim, passa a considerar o psicólogo como um "profissional do encontro", significando que este estará sempre em contato com a alteridade, seja com uma pessoa, instituição ou grupo. E acredita que

Mesmo que cheguemos a este encontro com a relativa e muito precária segurança de nossas teorias e técnicas, o que sempre importa é a nossa disponibilidade para a alteridade nas suas dimensões de algo desconhecido, desafiante e diferente; algo que o outro nos obriga a um trabalho efetivo e intelectual; algo que no outro nos pro-pulsiona e nos alcança; algo que do outro se impõe a nós e nos contesta, fazendo-nos efetivamente outros que nós mesmos (Figueiredo, 1993, p. 93).

Toda essa tematização da formação geral do psicólogo clínico tem o intuito de apontar que, mesmo no contexto de outras abordagens psicoterápicas, a prática sempre estará atravessada pela experiência ou modo de ser do psicólogo. O que esse autor pensa a respeito do contínuo processo de devir que faz parte da existência, reitera a reflexão que fazemos aqui sobre o que ocorre na formação e na prática do psicólogo na perspectiva abordada, evocando a condição de processo, experiência e indeterminação do Dasein. Com isso, não basta adotar uma teoria ou uma técnica psicoterápica para ter garantida a sua efetividade, eficácia ou correta aplicação. Ainda que no âmbito de uma mesma teoria, de um aprendizado comum a todos que a compartilham, a experiência de estar com o outro, enfim, de ser-no-mundo, afasta qualquer possibilidade de se experienciar um modo-de-ser apartado da própria experiência. É na multiplicidade que nos constitui, que se torna possível a abertura às distintas singularidades e alteridades do outro. $\mathrm{O}$ que seria isso senão a abertura ao velamento-desvelamento que constitui o modo-de-ser-humano?

Tais argumentos nos fazem lembrar o lugar da teoria na formação do psicólogo clínico. Não é incomum que se privilegie e se reconheça a primazia da teoria na formação do psicólogo, resultado de um pensamento que valoriza a técnica, passando a considerar o psicólogo clínico como um técnico. Diante da diversidade já apontada antes e considerando-se a complexidade do ser humano, as ideias mencionadas sugerem que o psicólogo clínico deveria aprender um maior número de técnicas e teorias que pudessem habilitá-lo e instrumentalizá-lo para o exercício da psicoterapia e das práticas clínicas. É nessa direção que Figueiredo (1996, p. 40) interroga: devemos conceber o psicólogo clínico como um ofertador de serviços (bens) a serem consumidos e a serem avaliados e regulados pela lógica e pela ética do mercado e dos direitos do consumidor? - ou o psicólogo clínico deve ser entendido como um dispositivo terapêutico, mas também histórico?

\section{O lugar da compreensão na clínica fenomenológico- existencial}

Na direção contrária ao pensamento preponderante na psicologia científica, a fenomenologia-hermenêutica heideggeriana considera a indeterminação do Dasein e sua impermanência; e tal modo de pensar sugere uma formação do psicólogo que rompa os modelos ancorados no domínio das teorias e técnicas psicoterápicas. Assim sendo, o fazer clínico seria norteado pela abertura do psicólogo às possibilidades que se desvelam na sua existência, na sua condição de ser-no-mundo-com-outros, cujos sentidos de ser não poderão ser dados a priori, o que significa arriscar-se na aventura de ser-no-mundo com todas as implicações da sua condição existencial. Uma delas é a disponibilidade de lançar-se no desconhecido, na experiência originária de ser-com-o-outro, ou seja, lançar-se ao nada, ao não-saber. De onde se pode depreender que o modo de ser profissional não está apartado do modo 
de ser humano. Neste momento não posso me furtar da lembrança do velho Carl Rogers, ao propor "um jeito de ser" que o terapeuta leva à sua prática. A fenomenologia hermenêutica, nos seus fundamentos ontológicos, me diz, hoje, que essa abertura e provisoriedade do existir são constitutivas do ser. $\mathrm{Ou}$ seja, é próprio do Dasein existir na experiência de ser afetado no sendo-no-mundo, numa disposição afetiva frente às demandas que lhe vão ao encontro. Enfim, a ideia de uma existência que significa abertura e desvelamento de sentidos.

Todas essas reflexões me fazem retornar ao pensar, como referido no início deste texto. Recorro às ideias de Critelli (2011), as quais traduzem, com clareza, o pensamento que aqui desejo desenvolver. A autora empreende uma reflexão em torno da aproximação entre filosofia e psicologia. E com tal intuito se debruça sobre a diferença entre o pensar, que seria uma atividade da filosofia, e a compreensão, a qual, seguindo as ideias de Hanna Arendt, também representa um ato do pensar:

A filosofia, assim, é um pensar profundo na busca de significados últimos e sem pressa. E a compreensão é um ato de pensar que também busca o significado dos acontecimentos, mas não de forma genérica. A compreensão emerge e responde às urgências da vida, partindo da concretude da existência e retornando a ela. Segundo Arendt, a compreensão se põe em movimento quando algum evento nos faz "perder nosso lugar no mundo" e, enquanto não compreendermos suas razões e seu sentido, não conseguimos nos reconciliar com o curso da vida e nos reinstalar no mundo (Critelli, 2011, p. 23).

Essa reflexão vai ao encontro do pensamento contido na Analítica da Existência, em que a compreensão é co-originária, ou seja, faz parte do ser-no-mundo. O que me faz recordar alguns momentos de supervisão, quando refletimos sobre os modos de se abordar ou interpretar o sentido na experiência de sofrimento presente na relação terapêutica. Não raramente, se apresenta uma dificuldade de entendimento em relação à postura compreensiva do psicólogo no momento da fala-escuta do seu cliente-paciente. O que remete à compreensão como uma forma de pensar, ilustrada pelas palavras de Sá (2002) que, de forma clara, traduzem a pertinência entre pensar e compreensão, em referência à clínica psicológica:

O pensamento que libera a essência da técnica na direção de uma realização transformadora não é o pensar já interpretado de modo técnico como um cálculo de razões. A essência do pensamento não se encontra na representação dos entes, mas na memória do ser. Pelo pensar, o homem é levado à sua essência e vela pela essência de tudo que é. O pensamento não é uma função psicológica ou a atividade de um sujeito transcendental; o pensamento pertence ao âmbito da linguagem, onde homem e ser habitam em correspondência (p. 7).

O próprio filósofo, Heidegger, já anunciava que "O homem atual está em fuga de pensamento" (1959, p. 12). O filósofo entende que existiriam dois tipos de pensamento, segundo ele, "legítimos e necessários: o pensamento que calcula e a reflexão (Nachdenken) que medita" (p. 13). É possível levar tal reflexão à formação do psicólogo na perspectiva fenomenológico-existencial, cujo modo-de-ser ancora a atitude fenomenológica. Estou certa de que a filosofia representa não só um caminho para se pensar a existência, mas também para transformá-la. Inspirada por essas ideias, podemos propor que o fazer clínico seria norteado pela abertura do psicólogo às possibilidades que se desvelam na sua existência, na sua condição de ser-no-mundo-com-outros, cujos sentidos de ser não poderão ser dados a priori, o que significa arriscar-se na aventura de ser-no-mundo com todas as implicações decorrentes dessa condição existencial. Uma delas é a disponibilidade de lançar-se no desconhecido, na experiência originária de ser-com-o-outro, ou seja, lançar-se ao nada, ao não-saber. Mais uma vez recorro às palavras de Sá (2010) para ilustrar essa ideia:

Para Heidegger, pensar em um modo próprio sobre o ser é pensar sobre aquilo que não é ente algum, que, portanto, não é. A questão do ser não pode excluir o não ser. A questão do ser é a questão do não ser, é a questão do nada, do vazio, do mistério. (p. 181)

O que me leva à convicção de que a formação não envolve somente o aprendizado de teorias e técnicas; na verdade, as transcende. A formação, portanto, estaria mais relacionada ao desenvolvimento de uma atitude, um modo de ser, de ver e de estar no mundo. E isso nos coloca, profissionais, professores e supervisores, numa posição a ser pensada e repensada, já que somos afetados naquilo que estamos fazendo e produzindo, seja na direção de tal atitude, seja em outra direção. É nesse sentido que Dutra (2008) afirma:

É difícil, também para nós, supervisores, "transmitir" um conhecimento do que seja uma escuta clínica, uma vez que, por consistir numa atitude, como a entendemos, o seu desenvolvimento passa, necessariamente, pela vivência de um modo de ser, por uma disponibilidade de abertura ao outro, o que, de alguma forma, conduzirá a pessoa aos seus "outros"; por isso a necessidade de arriscar-se nessa aventura de disponibilizar-se igualmente para si e para o outro, em direção a um universo desconhecido. (p. 226).

O horizonte, quando assim pensamos, é a existência. Como diz Heidegger (1927/1999): 
Chamamos existência ao próprio ser com o qual a pre-sença pode se comportar dessa ou daquela maneira e com o qual ela sempre se comporta de alguma maneira. (...) A questão da existência sempre só poderá ser esclarecida pelo próprio existir. A compreensão de si mesma que assim se perfaz, nós a chamamos de compreensão existenciária. Entendemos a existencialidade como a constituição ontológica de um ente que existe. (p. 39)

Devo ressaltar que reconheço a importância dos conhecimentos teórico-metodológicos para o exercício desse saber-fazer; porém chamo a atenção, sobretudo, para o modo de ser de cada um de nós, refletido em nossos saberes e fazeres no campo da psicologia e na vida; ou seja, enquanto existentes. A esse respeito, Sá, Azevedo Junior \& Leite (2010), referindo-se à supervisão de estágio, dizem:

Para a perspectiva fenomenológico-existencial, o saber sobre a existência é sempre problemático pela própria natureza desta, pois qualquer objetivação do existir afasta sua realidade essencial. Não é, portanto, objetivo da supervisão resolver o problema da identidade profissional utilizando da mera transmissão de teorias e técnicas, mas sustentar a tensão desta problematicidade, para que por meio dela se operem transformações existenciais, já que o saber que aqui mais importa é aquele indissociável do nosso próprio modo de ser (p. 137).

Pensando também na direção da formação, sobre a facticidade do Dasein e seu caráter mundano, Gemino (2002, p. 385) se junta a essa ideia. Ele diz:

O esforço contido no pensamento heideggeriano na radicalização da hermenêutica trazendo-a ao nível da facticidade cria condições para uma retomada da questão sobre formação em psicologia clínica de modo a permitir afirmar que, para além das teorias psicológicas e da própria práxis acadêmica, é nas raízes de nossa própria existência cotidiana que se encontram os elementos principais que constituem nossa identidade profissional.

As ideias apresentadas até agora reafirmam que a relação entre psicólogo/psicoterapeuta e sofrente, na prática e na experiência vividas no momento do encontro, dificilmente se pautará somente na “técnica” e na “teoria”. Já que existe uma dimensão existencial, uma experiência (no sentido de disposição afetiva ou Befindlickeit), criadora de sentidos diante das possibilidades que surgem na abertura do estar-no-mundo-com-outros. Refiro-me à singularidade do psicólogo, dimensão esta que também envolve o seu conhecimento e saber, formal e informal, os quais passam a constituir o seu modo-de-ser-terapeuta. Significa que a teoria, já incorporada ao seu modo de ser, junto à visão de homem e de mundo, passa a constituir uma atitude, um conhecimento tácito, como bem afirma Figueiredo (1993). Para ele, "a experiência pessoal é origem, destino e contexto de significação de toda teoria" (Figueiredo, 1996, p. 90).

\section{Pensamento meditante: um caminho}

Aqui cabe um retorno às ideias de Heidegger, ao apontar o caminho do pensamento como uma maneira de se lidar com a técnica e que pode ser pensado como uma direção a ser valorizada na formação do psicólogo clínico: "Este caminho é um caminho de reflexão" (Heidegger, 1959, p. 23). E para chegar a esse caminho ele propõe um modo de abertura traduzido como serenidade (Gelassenheit) e que Sá (2002), interpretando o filósofo, entende que esta seria "uma postura em que a alma se coloca igualmente aberta e desapegada em presença de todas as coisas" (p. 10). A serenidade, portanto, constitui o pensamento meditante o qual, segundo o mesmo autor, "nos solicita a uma atenção livre de qualquer violência subjetiva, isto é, de qualquer identificação a um aspecto exclusivo das coisas". E continua dizendo: "a conduta e a identidade profissional do terapeuta jamais se reduzem a uma questão de escolha teórica ou do aprendizado de técnicas, mas implica sua singularidade existencial como um todo, incluídos aí todos os seus saberes não conceituais e até mesmo os não representacionais” (p. 15).

Tomando como referência as ideias refletidas até aqui, podemos dizer que escolher um caminho profissional pautado na perspectiva fenomenológico-existencial implica um determinado olhar sobre os entes e o mundo. Um olhar que interroga, que não aceita, passivamente, as verdades instituídas. Um olhar que na clínica, por exemplo, não adota, sem questionar, os rótulos instituídos pelos campos de saber que costumam nomear e classificar, de forma generalizada, o sofrimento, de acordo com os seus manuais de transtorno mentais, já tão bem assimilados pelo senso comum. A atitude fenomenológica se ancora num modo-de-ser, e portanto, se faz a cada momento da experiência. Com isso, penso que a formação trataria de criar espaços nos quais esse olhar que interroga pudesse se expressar e, sobretudo, sustentar as tensões que essa forma de ser e de um não-saber, favorecem. Proponho que um caminho primordial na formação sobre a qual refletimos, seria exercitar um fazer-saber pautado na experiência singular, exercitando o pensamento meditante, uma vez que "O pensamento que calcula não é um pensamento que medita (ein besinnliches Denken), não é um pensamento que reflete (nachdenkt) sobre o sentido que reina em tudo que existe" (1959, p. 13). Para o filósofo, o caminho do pensamento que medita sobre o sentido das coisas também não representa um caminho fácil, e afirma que 
(...) um pensamento que medita surge tão pouco espontaneamente quanto o pensamento que calcula. O pensamento que medita exige, por vezes, um grande esforço. Requer um treino demorado. Carece de cuidados ainda mais delicados do que qualquer outro verdadeiro ofício. Contudo, tal como o lavrador, também tem de saber aguardar que a semente desponte e amadureça. (Heidegger, 1959, p. 14).

Assim, nos resta levar adiante esse caminho e o que poderia significar no contexto da formação. O próprio filósofo acena com uma possibilidade, esta bem alentadora:

Por outro lado, qualquer pessoa pode seguir os caminhos da reflexão à sua maneira e dentro dos seus limites. Por quê? Porque o homem é o ser (Wesen) que pensa, ou seja, que medita (sinnende). Não precisamos, portanto, de modo algum, de nos elevarmos às <regiões superiores> quando refletimos. Basta demorarmo-nos (verweilen) junto do que está perto e meditarmos sobre o que está mais próximo: aquilo que diz respeito a cada um de nós, aqui e agora; aqui, neste pedaço de terra natal; agora, na presente hora universal (p. 14).

As palavras do filósofo atestam que não é possível abdicar de um modo-de-estar-no-mundo nem mesmo quando se está diante de um contexto dito científico. É nessa direção, ou seja, no desenvolvimento de uma postura fenomenológica, no exercício da serenidade e na certeza de um poder-ser, que a formação do psicólogo clínico nesta perspectiva se pauta.

\section{Concluindo}

Ao final dessas reflexões constato que muitas questões foram lançadas, pensadas e refletidas. Não trago respostas conclusivas e definitivas, como era de se esperar, uma vez que estamos tratando de uma prática clínica que representa muito mais uma postura do que a aplicação de teorias e técnicas psicológicas. Portanto, as reflexões empreendidas aqui visam a enriquecer o diálogo e a interlocução entre todos os que compartilham as preocupações surgidas no âmbito da formação de psicólogos. Cabe, agora, esperar que as ideias compartilhadas possam seguir adiante e contribuir para um diálogo profícuo e atual entre aqueles que se relacionam com o campo da psicologia clínica.

\section{Referências}

Critelli, D. (2011). Psicologia e Fenomenologia (Filosofia e Terapia). In J. O. Breschigliare \& M.C. Rocha (Orgs.). SAPServiço de Aconselhamento Psicológico: 40 anos de história (p. 19-28). São Paulo: SAP/IPUSP.
Dicionário Aurélio On Line (2013). http://www.dicionariodoaurelio.com/Formacao.html. Acessado em 28 de agosto de 2013.

Dutra, E. (2008). Afinal, o que significa o social nas práticas clínicas fenomenológico- existenciais? Estudos e Pesquisas em Psicologia (UERJ), 8 (2), 221-234.

Dutra, E. (2009). Parâmetros técnicos e éticos para a formação do psicoterapeuta: alguns apontamentos. In Conselho Federal de Psicologia, Ano da Psicoterapia. Textos Geradores (p. 57-67). Brasília: CFP.

Figueiredo. L. C. (1993). Sob o signo da multiplicidade. Cadernos de subjetividade (PUC-SP), 1, 89-95.

Figueiredo, L. C. (1996). Revisitando as Psicologias: Da Epistemologia à Ética nas Práticas e Discursos Psicológicos. São Paulo: EDUC/Petrópolis, Vozes.

Figueiredo, L. C. \& de Santi, P. L. R. (2000). Psicologia, uma (nova) introdução; uma visão histórica da psicologia como ciência. São Paulo: EDUC.

Gemino, A. M. (2002). Sobre o lugar da teoria na formação do psicólogo clínico: uma abordagem hermenêutica. Arquivos Brasileiros de Psicologia, 54(4): 377-385.

Heidegger, M. (1959) Serenidade. Lisboa: Instituto Piaget.

Heidegger, M. (1999) Ser e Tempo. $8^{\mathrm{a}}$ ed. Petrópolis, R.J., Vozes, v. I e II (Original publicado em 1927).

Heidegger, M. (2001). A Questão da Técnica. Em Martin Heidegger, Ensaios e Conferências (p. 11-38). Petrópolis: Vozes (Original publicado em 1953).

Sá, R. N. (2002). A psicoterapia e a questão da técnica. Arquivos Brasileiros de Psicologia (UERJ), 54(4), 348-362.

Sá, R. N. (2010). A analítica fenomenológica da existência e a psicoterapia. In: Tédio e Finitude: Da filosofia à psicologia (p. 177-199). In Ana M.L.C.Feijoo (Org.). Belo Horizonte: Fundação Guimarães Rosa.

Sá, R. Novaes; Azevedo Junior, O. \& Leite, T. L. (2010). Reflexões fenomenológicas sobre a experiência de estágio e supervisão clínica em um serviço de psicologia aplicada universitário. Revista da Abordagem Gestáltica, 17(2): 135-140.

Safra, G. (2004). A pó-ética na clínica contemporânea. Aparecida-SP, Ideias \& Letras.

Elza Dutra - Psicóloga e psicoterapeuta. Doutora em Psicologia Clínica pela Universidade de São Paulo (USP), e Docente do Programa de Pós-Graduação em Psicologia da Universidade Federal do Rio Grande do Norte (UFRN). Endereço Institucional: Universidade Federal do Rio Grande do Norte, Centro de Ciências Humanas Letras e Artes, Departamento de Psicologia. Campus Universitário, Lagoa Nova, s/n. CEP: 59.075-970. Natal, RN. E-mail: elzadutra.rn@gmail.com

Recebido em 03.09.13 Primeira Decisão Editorial em 07.11.13 Aceito em 26.11.13 